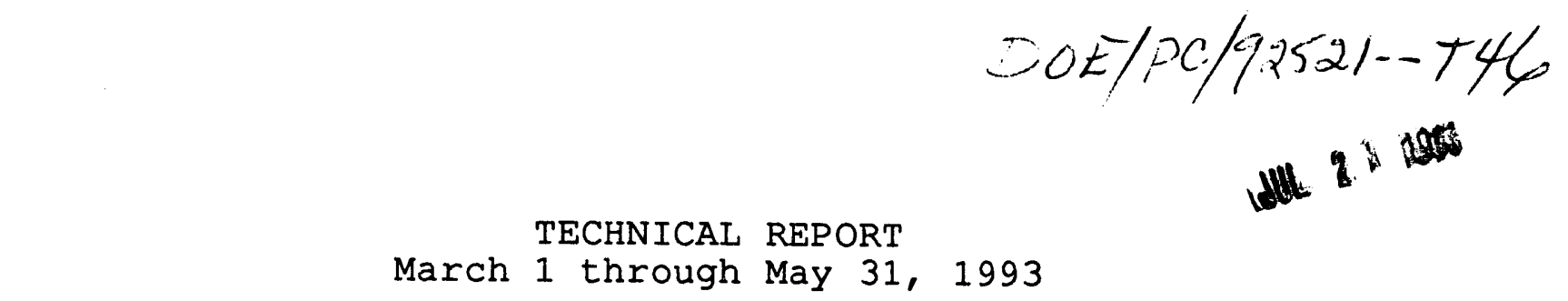

\title{
Project Title: ANALYSIS OF ORGANIC SULFUR AND NITROGEN IN COAL VIA TANDEM DEGRADATION METHODS DE-FC22-92PC 92521
}

Principal Investigator: Michael A. Kruge, Dept of Geology,

Other Investigators:

Southern Illinois University

Project Manager:

Stephen R. Palmer, Dept of Geology,

Southern Illinois University

Ken Ho, Illinois Clean Coal

Institute

\section{ABSTRACT}

With the recent increase in concern for environmental issues and the implication of sulfur and nitrogen in coal combustion products as prime causes of acid rain, it has become clear that there is an urgent need for alternative methods for determining the nature of organic sulfur and nitrogen compounds in coal. In our research, we apply chemical and thermal degradation techniques to render coal amenable to standard GC characterization.

Standard density gradient centrifugation successfully isolated vitrinite from the IBC101 coal, whereas the multi-step high resolution method was required to isolate liptinite and inertinite macerals, which are minority constituents. Analytical pyrolysis-gas chromatography, operating with either the sulfur selective flame photometric detector (py-GC-PFD) or a mass spectrometer $(\mathrm{py}-\mathrm{GC} / \mathrm{MS})$, provides distinctive organosulfur "fingerprints" for all coal, asphaltene and maceral samples analyzed to date. Py-GC/MS permits ready differentiation of asphaltenes from low and high rank coals. of the two pyrolysis techniques, py-GC-FPD is simpler and less expensive, and is the recommended method for situations in which sulfur content is the prime concern. Both py-GC methods are superior to oxidative degradation techniques in that they are permit direct, one-step micro-scale analysis, requiring only a minimum of sample preparation. Distinctive chromatographic profiles are also achieved using the methylated dichromate oxidation products of coals, asphalteiles and macerals, but the extensive wet chemical preparation required is a serious disadvantage. Reasonable matches for the expected masses of alkylthiophene carboxylic acid derivatives have been found in the direct probe, low voltage, high resolution mass spectral data set collected on the methylated dichromate oxidation products of the sulfur-rich Spanish lignite sample, providing an additional line of evidence confirming the presence of such compounds.

U.S. DOE Patent Clearance is NOT required prior to publication of this document.

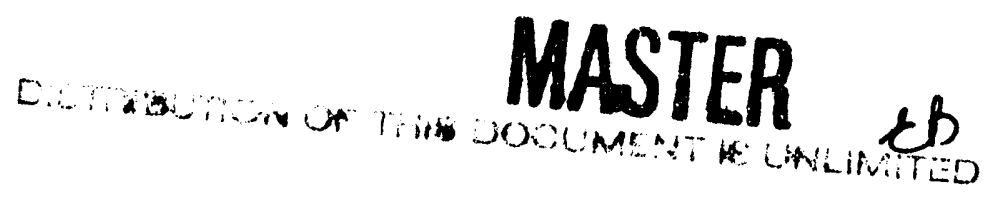




\section{EXECUTIVE SUMMARY}

With the recent increase in concern for the environment, understanding the nature of organic sulfur and nitrogen in coal has become a pressing issue, as they are among the precursors of acid rain. Essential to the development of successful clean coal technologies is the need to characterize the different forms of organic sulfur and nitrogen that occur in coal. Only when this has been done will it be possible to design the required processes for their effective removal. Attempts to characterize organic sulfur in coal have included many different techniques but the necessary detailed information still eludes the scientific community. This is largely due to the immense task of characterization and to the fact that no one technique can provide all the answers. Degradative methods employing chemical and thermal processes can provide detailed molecular information, but they suffer from the inability to characterize all of the sulfur at one time, and the possibility of regressive and/or rearrangement reactions. On the other hand, bulk spectroscopic ("non-destructive") techniques can observe all of the forms of sulfur simultaneously and in situ. However, most non-destructive techniques are not readily available to the general scientific community and suffer from the inability to gather detailed molecular information. At best, sulfur compounds are resolved only into general types and hence information such as the nature of substituents and substitution patterns are not available. All information is needed for desulfurization strategies. The present study undertakes a combination of chemical and thermal degradation techniques for the enhanced characterization of organic sulfur and organic nitrogen in coal.

The specific objectives of Year 2 of this study are to: 1) apply oxidative degradation methods and subsequent chromatographic analysis to a variety of coals and coal derivatives as a means of elucidation of their chemical structure, with emphasis on their organic sulfur and nitrogen forms. During Year 1 of the project, two oxidation methods were determined to be the most useful. oxidation by peroxyacetic acid is very thorough and can provide a picture of the overall coal structure. oxidation by sodium dichromate is milder, preserving details of the structure of organic sulfur compounds in particular. 2) apply analytical micropyrolysis techniques, in tandem with the two oxidative methods, to the same suite of samples. This approach will provide a second line of evidence to support findings of the oxidation experiments. 3) analyze all relevant samples from the Illinois Basin Coal Sample Program bank to ascertain the extent of variation in organic sulfur structures in the region. 4) analyze a series of Appalachian coals a) to compare organic sulfur structures with those in Illinois and

b) to examine the effect of coal rank on organic sulfur type.

5) analyze several coals of extraordinarily high organic 
sulfur content, which will make for much easier detection and characterization of organic sulfur structures. Thus, it is anticipated that by comparing the degradation products of the Illinois coal with those of the higher sulfur coals, a much better understanding of the sulfur chemistry of the Illinois coal will be obtained. 6) apply the degradative techniques developed on whole coal and macerals to coal asphaltenes, since they are believed to be polymeric structures similar to the whole coal, but smaller and more readily analyzed. 7) develop a routine methodology for the assessment of the nature of organic sulfur in any coal sample.

standard density gradient centrifugatiion successfully isolated vitrinite from the IBC101 coal, whereas the multistep high resolution method was required to isolate liptinite and inertinite macerals. The technique was not able to further fractionate the liptinite group into its constituent cutinite, resinite and sporinite macerals, probably because of the low concentration of liptinites in this samples.

Analytical pyrolysis-gas chromatography, operating with either the sulfur selective flame photometric detector (pyGC-PFD) or a mass spectrometer (py-GC/MS), provides distinctive organosulfur "fingerprints" for all coal, asphaltene and maceral samples analyzed to date. Asphaltenes from low (high volatile bituminous $C$ ) and high rank (medium volatile bituminous) coals from the Lower Kittanning seam are readily differentiated by the alkylthiophene distributions on their py-GC/MS traces. Elemental sulfur dominates the pyGC/MS trace of a low volatile bituminous sample.

Py-GC/MS is advantageous, as it provides detailed information about the hydrocarbon components in addition to the organosulfur compounds. However, py-GC-FPD is simpler and less expensive and is the recommended method for situations in which sulfur content is the prime concern. Both py-GC methods are superior to oxidative degradation techniques in that they are permit direct, one-step microscale analysis, requiring only a minimum of sample preparation.

Distinctive chromatographic profiles are also achieved using the methylated dichromate oxidation products of coals, asphaltenes and macerals. Alkylthiophene carboxylic acid derivatives (ATCA compounds) continue to be seen in sulfurrich samples, but are not readily detectable in the sulfur lean coals, such as IBC109. In general, when choosing an analytical procedure for application on a routine basis, the extensive wet chemical preparation required for the oxidation methods is a serious disadvantage. There are also problems in reproducibility, apparently due to the sensitivity of product distribution to amount of starting material. Reasonable matches for ATCA compound mass spectral ions have been found in the direct probe, low voltage, high resolution MS data set, collected on the methylated dichromate oxidation products of the sulfur-rich Spanish lignite sample, providing an additional line of evidence confirming the presence of such compounds. 
OBJECTIVBS

The overall objective of this study is to continue the characterization of organic sulfur and nitrogen compounds in coal with greater thoroughness than has previously been attempted. The specific goals for the second year are:

1. To apply oxidative degradation methods and subsequent chromatographic analysis to a variety of coals and coal derivatives as a means of elucidation of their chemical structure, with emphasis on their organic sulfur and nitrogen forms. Iurjing Year 1 of the project, two oxidation methods were determined to be the most useful. oxidation by peroxyacetic acid is very thorough and can provide a picture of the overall coal structure. oxidation by sodium dichromate is milder, preserving details of the structure of organic sulfur compounds in particular.

2. In tandem with the two oxidative methods, to apply analytical micropyrolysis techniques to the same suite of samples. This approach will provide a second line of evidence to support findings of the oxidation experiments.

3. To analyze all relevant samples from the Illinois Basin coal Sample program bank, to ascertain the extent of variation in organic sulfur structures in the region.

4. To analyze a series of Appalachian coals a) to compare organic sulfur structures with those in Illinois and b) to examine the effect of coal rank on organic sulfur type.

5. To analyze several coals of extraordinarily high organic sulfur content, which will make for much easier detection and characterization of organic sulfur structures. Thus, it is anticipated that by comparing the degradation products of the Illinois coal with those of the higher sulfur coals, a much better understanding of the sulfur chemistry of the Illinois coal will be obtained.

6. To apply the degradative techniques developed on whole coal and macerals to coal asphaltenes, since they are believed to be polymeric structures similar to the whole coal, but smaller and more readily analyzed.

7. To develop a routine methodology for the assessment of the nature of organic sulfur in any coal sample.

\section{INTRODUCTION AND BACKGROUND}

Essential to the development of successful sulfur and nitrogen removal technologies is the need to characterize the different forms of organic sulfur and nitrogen that occur in coal. Only when this has been done will it be possible to design the required technologies for their effective removal. Attempts to characterize organic sulfur in coal have included many different techniques but the necessary detailed information still eludes the scientific community. This is 
largely due to the immense task of characterization and to the fact that no one technique can provide all the answers. Degradative methods employing chemical and thermal processes can provide detailed molecular information, but they suffer from the inability to characterize all of the sulfur at one time, and the possibility of regressive and/or rearrangement reactions. On the other hand, bulk spectroscopic ("nondestructive") techniques can observe all of the forms of sulfur simultaneously and in situ. However, most nondestructive techniques are not readily available to the general scientific community and suffer from the inability to resolve detailed molecular information. At best, sulfur compounds are resolved only into general types and hence detailed information such as the nature of substituents and substitution patterns are not available. All information is needed for desulfurization strategies.

oxidative and reductive techniques have been used extensively in attempts to elucidate the organic structure of complex organic solids such as coals, kerogens, humic acids and many other fossil fuel materials. In the vast majority of these studies the emphasis was to determine the carbon backbone of these materials and as a result very little information regarding the structures of heteroatom components was provided. This is especially true for organic sulfur and organic nitrogen species which are typically in low concentrations when compared to hydrocarbon structures.

With the recent increase in concern for environmental issues, there has been a shift in emphasis away from the determination of carbon structures in fossil fuels to the characterization of heteroatom structures, especially those containing organic sulfur and nitrogen. This has resulted in the development of a number of analytical techniques selective for sulfur and nitrogen. However, these techniques often produce conflicting data and consequently they are not universally accepted within the scientific community. Thus, there is an urgent need for alternative methods for characterizing organic sulfur and nitrogen compounds in coal. The present study undertakes a combination of chemical and thermal degradation techniques for the enhanced characterization of organic sulfur and organic nitrogen in coal.

\section{BXPERIMENTAL METHODS}

Eight coals from the Illinois Basin Coal Sample Program (nos. 101, 102, 104, 105, 106, 109, 110 and 111) have been obtained for investigation in Year 2 of this study. These samples will be referred to as IBC101, IBC102, etc. for purposes of these reports. The IBC101 coal was separated into concentrates of its constituent macerals during Year 1 and these macerals will be analyzed during this year. The other coal samples under investigation are the Rasa coal from Pakistan and a Spanish lignite (Lignito de Mequinenza), both of which have extraordinarily high organic sulfur contents. 
A series of 5 coals from the Lower kittanning seam of Pennsylvania will also be studied. These particular coals were chosen because of their wide rank range and high sulfur contents (Table 1), to assess the effect of coal rank on organic sulfur compounds. Experimental methods have been previously described [1].

Table 1 - Properties of the Lower Kittanning samples. (Source: The Pennsylvania State University coal database.)

\begin{tabular}{|c|c|c|c|c|}
\hline Sample & $\begin{array}{c}\text { Vol. Matter } \\
\text { (odaf) }\end{array}$ & $\begin{array}{l}\text { Vitrinite } \\
\text { Refl. (\&Ro) }\end{array}$ & $\begin{array}{c}\text { Total } \\
(z)\end{array}$ & $\underset{(z)}{\text { Organic } S}$ \\
\hline $\begin{array}{l}\text { SIU1900 } \\
\text { SIU1893 } \\
\text { SIU1905 } \\
\text { SIU1894 } \\
\text { SIU1896 }\end{array}$ & $\begin{array}{l}45.0 \\
44.5 \\
41.1 \\
27.2 \\
23.4\end{array}$ & $\begin{array}{l}0.65 \\
0.72 \\
0.87 \\
1.27 \\
1.42\end{array}$ & $\begin{array}{l}4.39 \\
5.25 \\
6.19 \\
4.43 \\
5.05\end{array}$ & $\begin{array}{l}2.25 \\
1.52 \\
1.30 \\
0.86 \\
1.22\end{array}$ \\
\hline
\end{tabular}

\section{RESULTS AND DISCUSSION FOR THIS QUARTER}

\section{Density Gradient Centrifugation}

Demineralized, extracted, floated IBC101 coal was separated by density gradient centrifugation, as described previously [2]. The standard DGC profile of this sample consists of a single large peak at $1.29 \mathrm{~g} / \mathrm{ml}$ (Fig. 1A), corresponding to vitrinite, which is the chief constituent of the coal (petrographically determined to comprise $88.6 \mathrm{vol}$. \%). To obtain improved separation of the minority constituents, high resolution DGC was employed, which requires a preconcentration of the sample by centrifugation in a solution of constant density, rather than a gradient [3]. To examine the lower density material, which contains the liptinite macerals (6.2 vol. of of the coal), the coal was floated at $1.25 \mathrm{~g} / \mathrm{ml}$ and then fractionated through a gradient ranging from 1.00 to $1.25 \mathrm{~g} / \mathrm{ml}$. The resulting profile shows no distinct peaks (Fig. 1B), but petrographic examination indicates that fractions between 1.05 and 1.15 contain mixed liptinites (cutinite, sporinite and resinite) with no significant vitrinite contamination. The technique was not able to further fractionate the liptinite group into its constituent cutinite, resinite and sporinite macerals, probably because of the low concentration of liptinites in this samples. Fractions between 1.15 and $1.25 \mathrm{~g} / \mathrm{ml}$ are mixtures of liptinite (primarily sporinite) and vitrinite. Two composite samples, liptinite and mixed liptinite/vitrinite, were prepared from this DGC run (Fig. 1B) for further chemical analyses. 


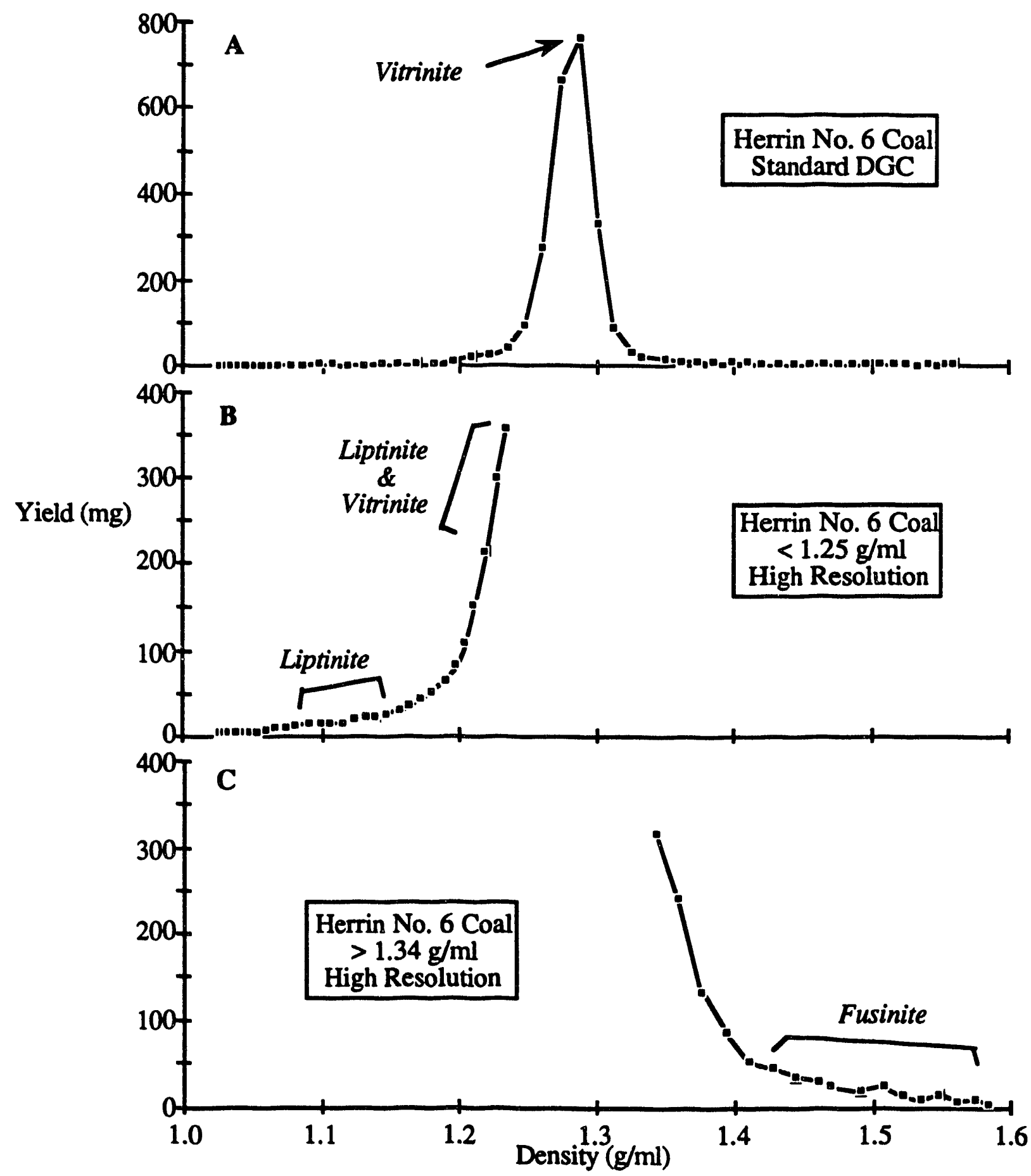

Figure 1 - Density gradient profiles for IBC101 coal.

To preconcentrate the inertinite macerals, which, at 5.2 vol. 8 , are the other principal minority constituents of the IBC101 coal, the "sink" remaining after floatation at a constant density of $1.34 \mathrm{~g} / \mathrm{ml}$ was separated by high resolution DGC over a $1.34-1.60 \mathrm{~g} / \mathrm{ml}$ range (Fig. 1C). While no distinct peaks are recognized on the DGC profile, good separation of inertinite from vitrinite was achieved in the 
fractions above $1.4 \mathrm{~g} / \mathrm{ml}$. Two composite samples for chemical analysis were prepared, both consisting predominantly of fusinite.

100

1
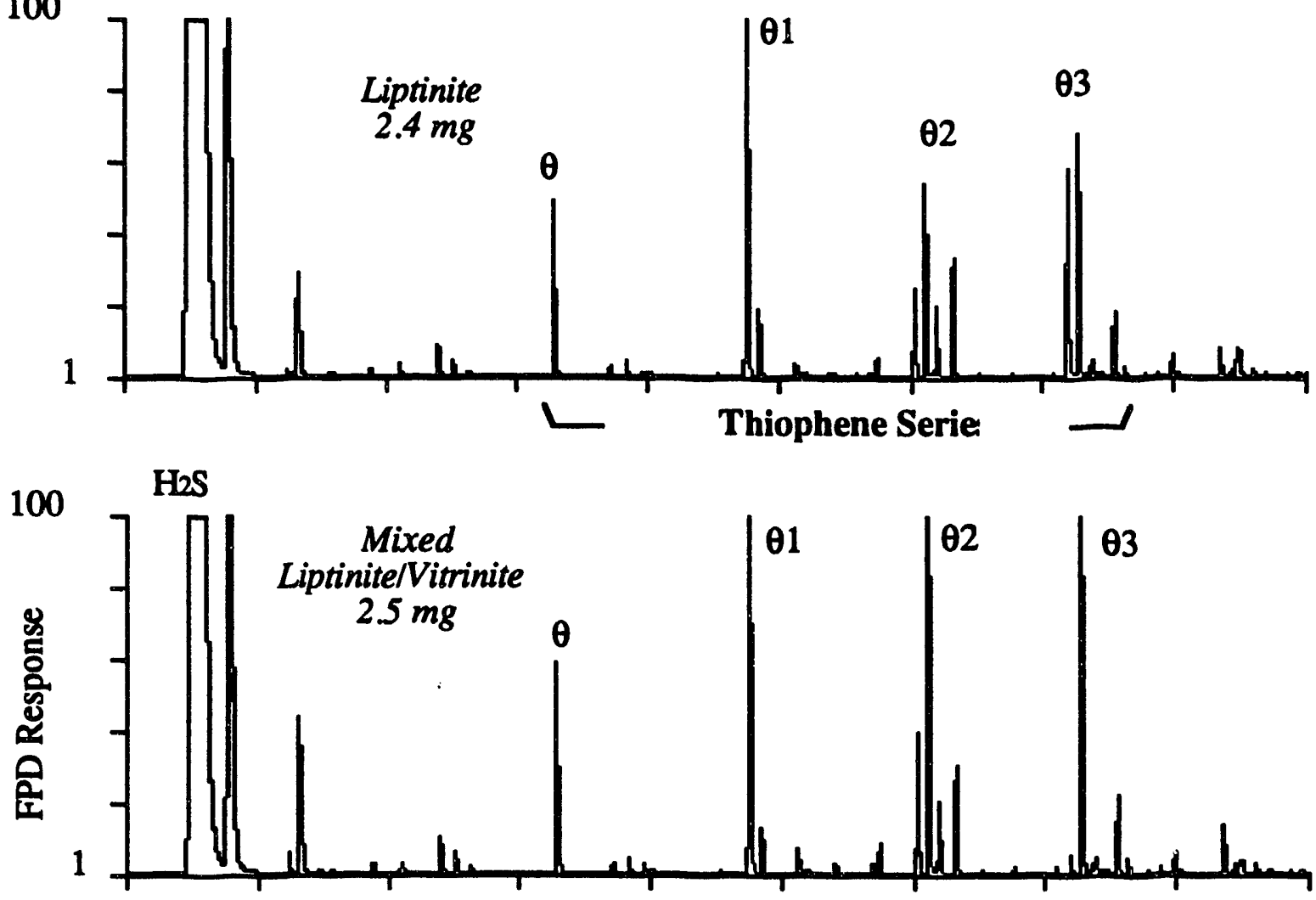

20

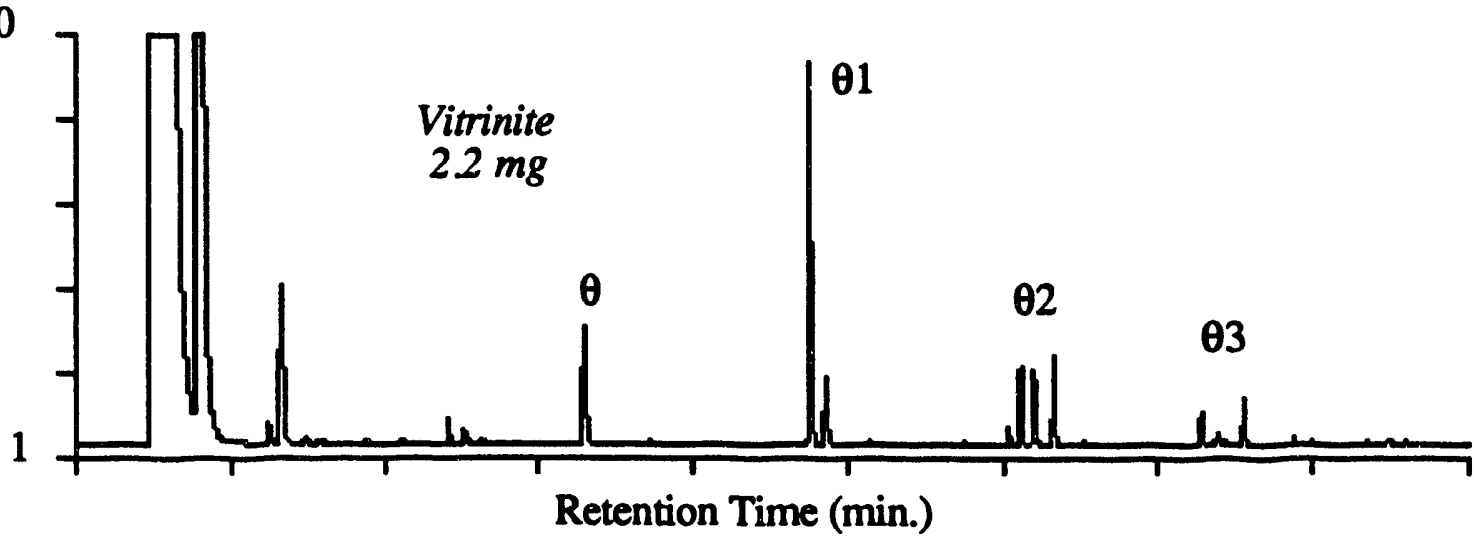

Figure 2 - PY-GC-FPD traces for IBC101 density fractions. A) Liptinite. B) Mixed liptinite/vitrinite. C) Vitrinite. see Table 2 for peak identifications.

Analytical Pyrolysis-Gas Chromatography

work on analytical pyrolysis-gas chromatography continued during the third quarter primarily using the sulfur-selective flame photometric detector (py-GC-FPD) and 
the mass spectrometer (py-GC/MS). Fig. 2 shows py-GC-FPD results from the IBC101 DGC fractions. The pyrolyzates are dominated by $\mathrm{H}_{2} \mathrm{~S}$ and thiophene and its simple alkyl derivatives $\left(\mathrm{C}_{1}-\mathrm{C}_{3}\right)$, as was noted previously for a variety of coal samples [4]. However, the distributions of thiophenes vary remarkably among the three samples, especially considering that they originated in a single coal. A single methylthiophene peak predominates in the vitrinite, whereas the liptinites produced the largest number of strong thiophene peaks. The mixed liptinite/vitrinite sample, while not containing well-separated macerals, was analyzod because it has the highest organic sulfur content [4]. Its unique distribution of thiophenes (Fig. 2C) suggests that it is not simply a mixture of the components seen in Fig. $2 \mathrm{~A}$ and $2 \mathrm{C}$. It may contain particularly sulfur-rich liptinite, whose corresponding greater density renders it inseparable from vitrinite.

It is interesting to note on Fig. 2 that the samples richer in sulfur (mixed liptinite/vitrinite, 4.17\% $\mathrm{S}$ and liptinite, $3.63 \% \mathrm{~S})$ have much greater FPD response than the vitrinite $(3.17 \% \mathrm{~S})$, even though approximately the same amount of sample was analyzed $(2.2$ to $2.5 \mathrm{mg})$. This is consistent with our previous py-GC-FPD results [4].

Table 2 - P:-GC-FPD peak identification for Figs. 2-4. Isomer assignments have been previously confirmed $[5,6]$.

$\theta$

$\theta 1$

thiophene

methylthiophenes

b 2-methylthiophene

c 3-methylthiophene

$\theta 2$

$\mathrm{C}_{2}$-alkylthiophenes :

d 2-ethylthiophene

e 2,5-dimethylthiophene

f 2,4-dimethylthiophene

g 2,3-dimethylthiophene

Q3

$\mathrm{C}_{3}$-alkylthiophenes:

The thiophenes can be examined in detail by studying the distributions of $C_{1}$ and $C_{2}$ alkylthiophenes on either py-GC-FPD traces [4] or on composite mass chromatograms from $\mathrm{py}-\mathrm{GC} / \mathrm{MS}$ data (Figs. 3 and 4 ). Both types of data are useful as "fingerprints" for the particular samples and are essentially equivalent, although the quadratic response of the FPD detector produces a vertically "stretched" appearance (compare Fig. 3A with peaks $\theta 1$ and $\theta 2$ on Fig. 2A). The advantage of the $M S$ method is that data on hydrocarbon products are collected simultaneously and useful quantitative organic sulfur indicators may be readily computed, such as the ratio of toluene to methylthiophene. The advantages of the FPD system are its relative simplicity and lower cost. Quantitative information can be produced by evaluating peak 
response in light of the amount of sample analyzed, as discussed above.

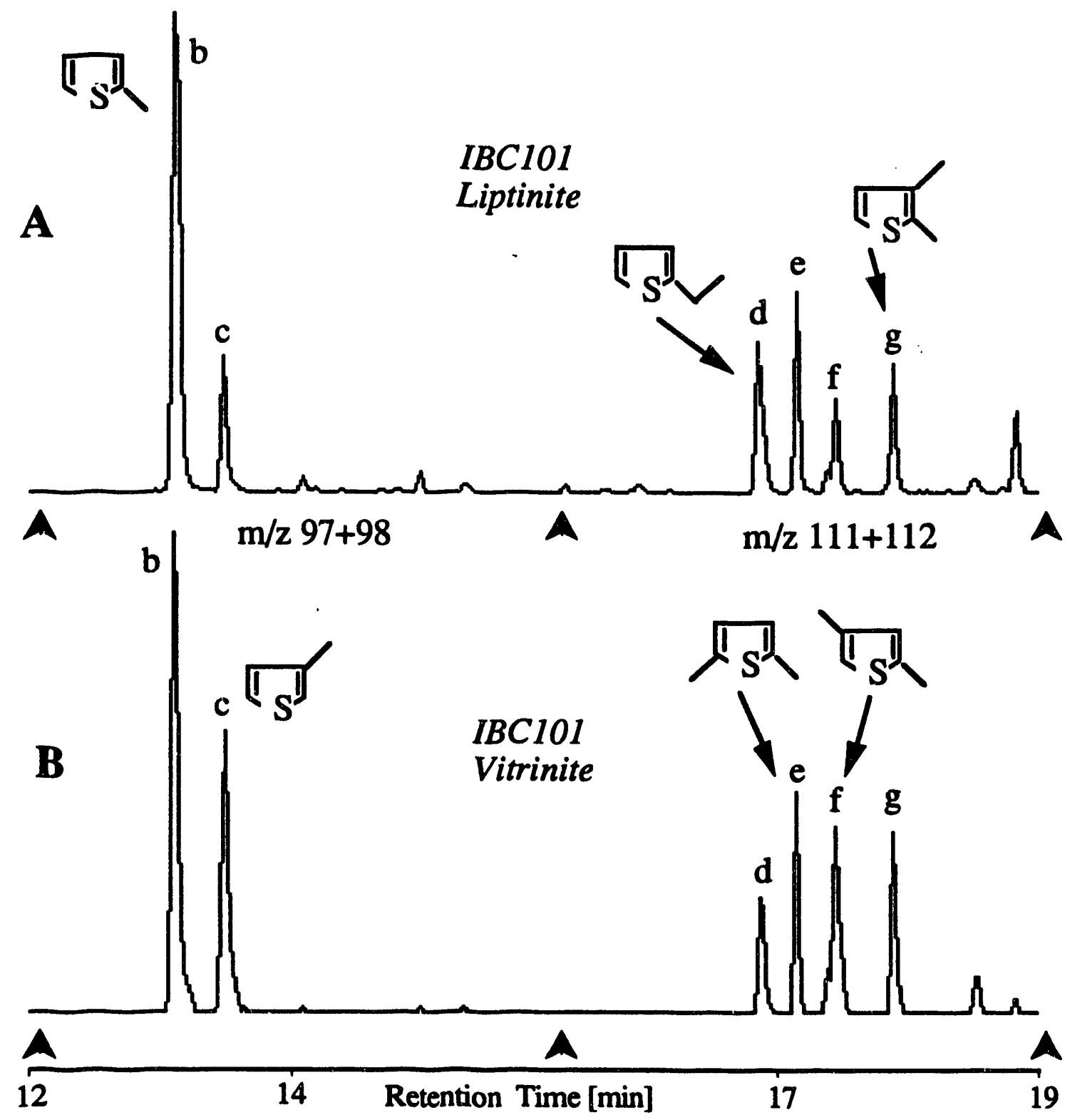

Figure 3 - Composite mass chromatograms showing methylthiophene $(\mathrm{m} / \mathrm{z} 97+98)$ and $\mathrm{C}_{2}$-alkylthiophene $(\mathrm{m} / \mathrm{z} 111$ +112 ) distributions for IBC101 liptinite and vitrinite. See Table 2 for peak identifications.

Comparing the py-GC/MS results for the IBC101 liptinite and vitrinite, it is apparent that there are considerable differences in the alkylthiophene distributions (Fig. 3). In particular, the greater prominence of 2-methylthiophene and 2-ethylthiophene in the liptinite imply greater "straight chain" hydrocarbon character in the liptinite, consistent with the high percentage of aliphatic compounds present in its pyrolyzate. 
The asphaltenes of the 5 Kittanning samples were also analyzed by py-GC/MS. The pyrolyzate of the asphaltene of the highest rank sample (SIU1896) contains a large elemental sulfur peak and only minor thiophenes, suggesting the natural fate of organic sulfur as coal rank approaches the low volatile bituminous level. The thiophene distributions of the pyrolyzates of the lowest (SIU1900) and second highest rank (SIU1894) Kittanning asphaltenes are presented in Fia. 4. The low rank sample has a relatively strong 2,4- and a weak 2,5-dimethylthiophene, in common with the asphaltenes from low rank Illinois Basin coals [4], but is distinctive in its relatively weak 2,3-dimethylthiopiene. The high rank asphaltene is radically different, having a strong predominance of the 3-methylthiophene.

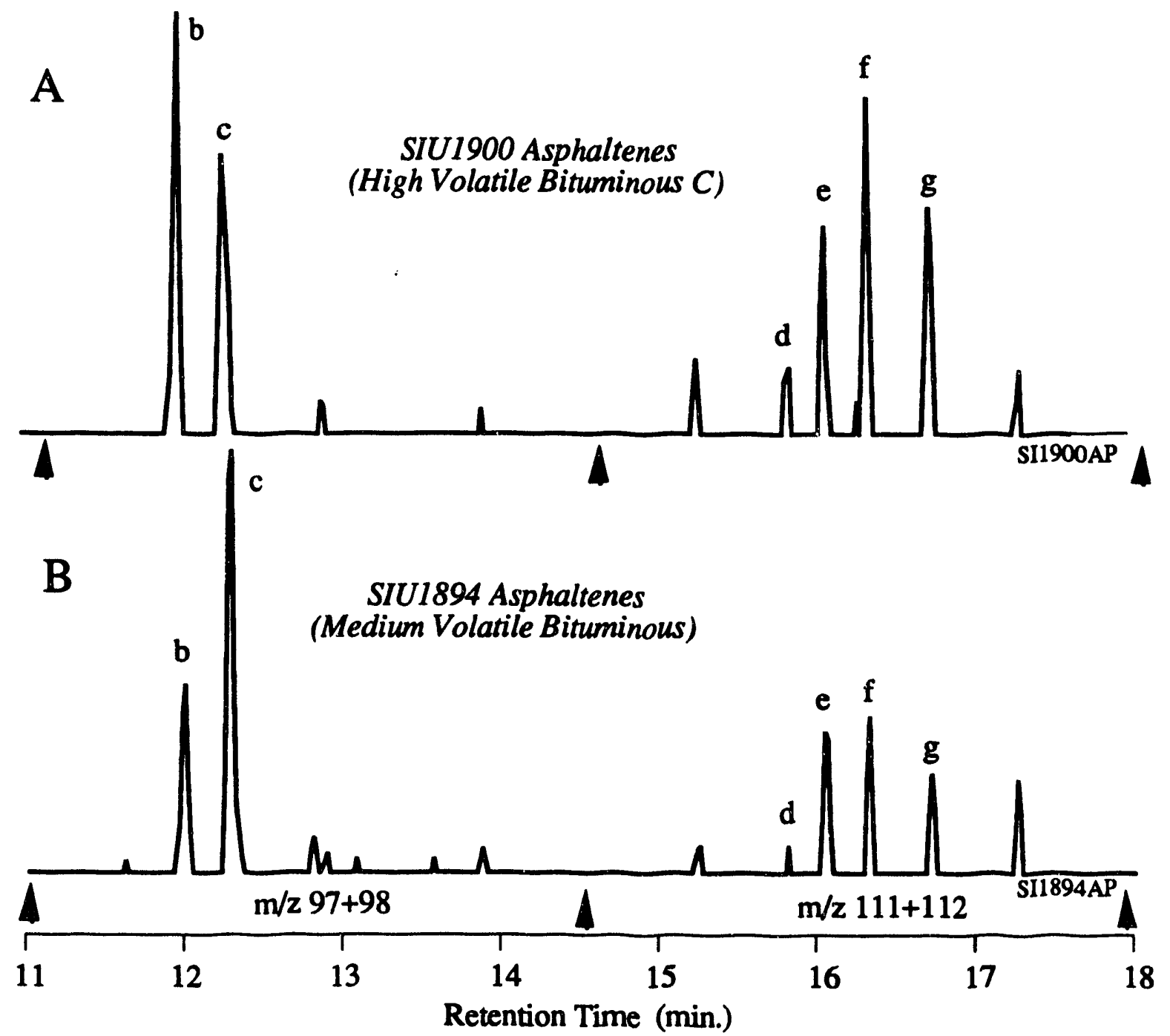

Figure 4 - Composite mass chromatograms showing methylthiophene $(\mathrm{m} / \mathrm{z} 97+98)$ and $\mathrm{C}_{2}$-alkylthiophene $(\mathrm{m} / \mathrm{z} 111$ +112 ) distributions for Lower Kittanning coal asphaltenes. See Table 1 for sample information and Table 2 for peak idencifications. 
The py-GC/MS technique is also suitable for the detection of organic nitrogen compounds. We have analyzed a sample of kerogen from the Monterey shale of California, a well-known petroleum source rock rich in marine organic matter, sulfur and nitrogen. The pyrolyzate of this sample contains alkylthiophenes and alkylbenzenes, as seen in the Illinois coal samples, but also a series of alkylpyrroles, which are nitrogen analogs to the thiophenes. The high concentration of nitrogen compounds in this kerogen (N/C ratio an order of magnitude greater than those in IBC coals) facilitates their recognition and identification [7]. We have also recognized alkylpyrroles as "minor constituents in other kerogens of marine origin. Careful examination of $\mathrm{py}-\mathrm{GC} / \mathrm{MS}$ data from the IBC samples, including the DGC fractions, indicates that such compounds are not detectable in carboniferous coal. Organic nitrogen in such coals must be assuming another form.

\section{Oxidation by Sodium Dichromate}

Chromatographic analysis of dichromate oxidation products continued in the third quarter. IBC104 is a high sulfur sample and its asphaltenes show strong alkylthiophene carboxylic acid derivative (ATCA) peaks (Fig. 5A). In contrast, ATCA peaks are barely discernible in the products of either the first or second oxidation step performed on the IBC109 coal, which is our sample lowest in sulfur (Figs 5B, 5C). The ATCA peaks, particularly 03 , are strong in the first oxidation step's products of the sulfur-rich IBC101 mixed liptinite/vitrinite DGC sample, but diminish after oxidation is repeated. The same phenomenon was noted for other samples [4]. The IBC101 vitrinite, also high in sulfur, shows strong $\theta 2$ and $\theta 3$ peaks.

In general, when choosing an analytical procedure for application on a routine basis, the extensive wet chemical preparation required for oxidation methods is a serious disadvantage. There are also problems in reproducibility, apparently due to the sensitivity of product distribution to amount of starting material [4]. 

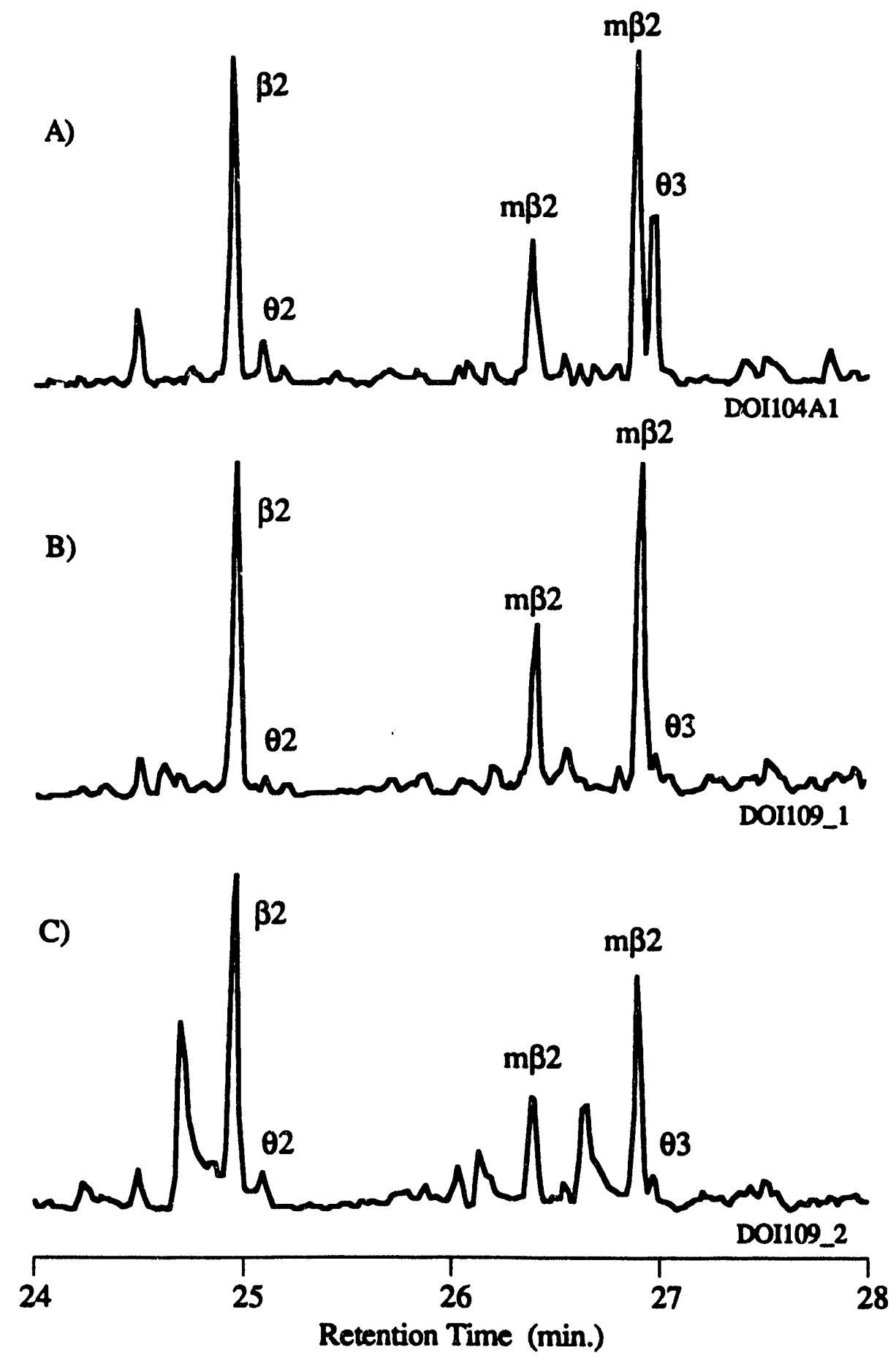

Figure 5 - Total ion current chromatograms over the 24-28 min. retention time range of methylated dichromate oxidation products showing benzene and methylbenzene dicarboxylic acids ( $\beta 2$ and $\mathrm{mB2}$ ) and ethyl and propylmethoxythiophene carboxylic acids $(\theta 2$ and $\theta 3)$, as methyl esters. A) IBC101 asphaltenes, 1st oxidation step. B) IBC109 coal, 1st step. C) IBC109 coal, 2nd step. 

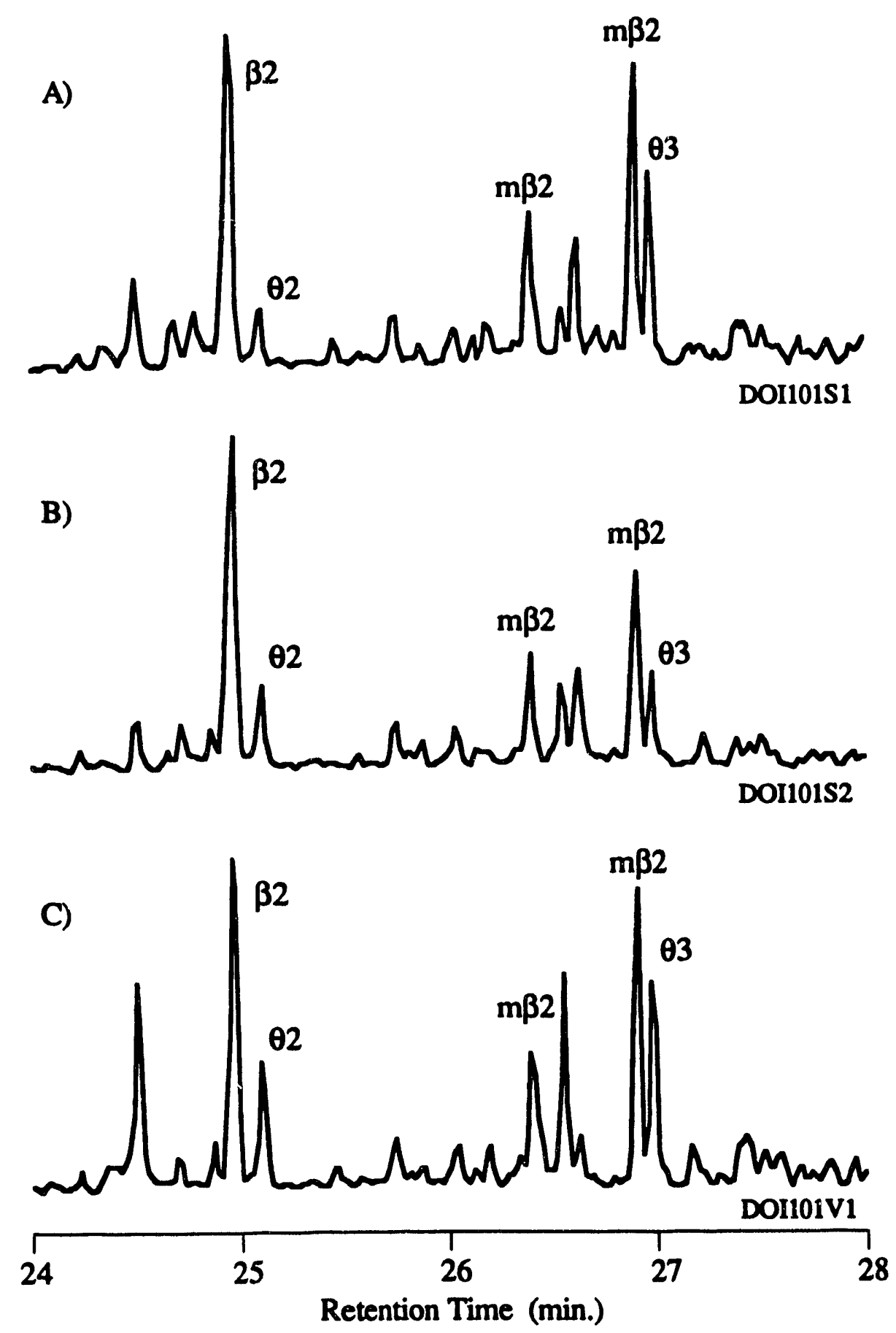

Figure 6 - Total ion chromatograms of dichromate oxidation products. A) IBC101 mixed liptinite/vitrinite, 1st oxidation step. B) Same, but 2nd step. C) IBC101 vitrinite, 1st step. Peak identifications as in Fig. 5.

High Resolution Mass Spectrometry

Several experiments using direct probe, low voltage high resolution mass spectrometry (HRMS) were performed to test the efficacy of the technique to provide supplemental evidence to confirm the identity of organosulfur compounds 
produced by mild oxidative degradation. Early efforts reported previously explored the optimization of the variables of probe temperature and MS ionizing voltage [8], however the high resolution capabilities of the instrument available on campus were not then in full operation. Now the instrument is running properly and our samples were resubmitted for high resolution experiments.

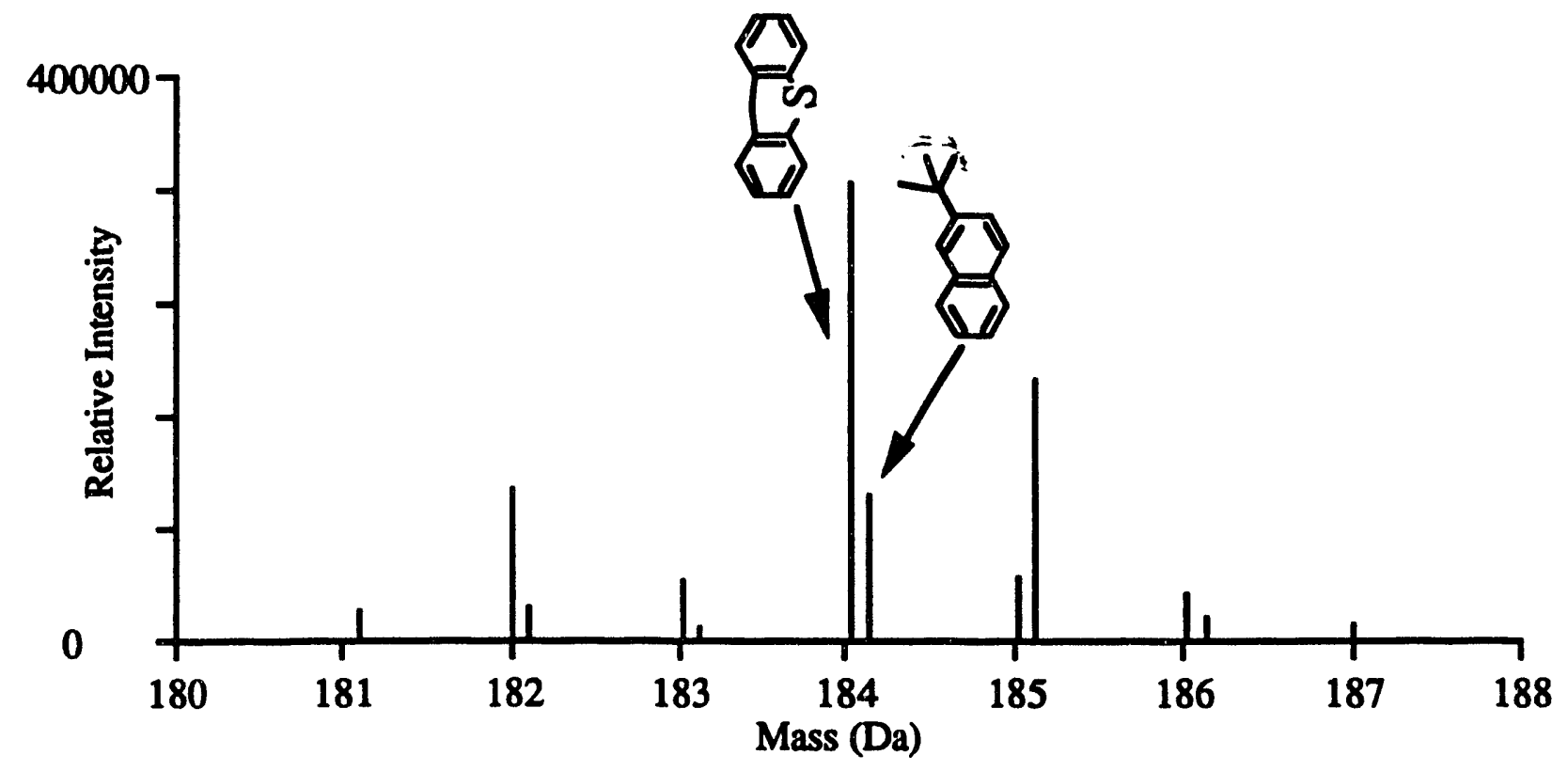

Figure 7 - HRMS spectrum (partial) of a mixture of 2isobutylnaphthalene and dibenzothiophene. Resolution $=5300$, ionizing voltage $=20 \mathrm{eV}$.

HRMS exploits the mass defects of heteroatoms such as sulfur to discriminate two molecules of the same nominal mass. To test the effectiveness of the system, we submitted two authentic standards with a nominal mass of $184 \mathrm{Da}$. These are 2-isobutylnaphthalene $(184.1270 \mathrm{Da})$ and dibenzothiophene $(184.0356 \mathrm{Da})$. The mass spectrum of an equimolar mixture of the two shows that the molecular ions are easily resolvable (Fig. 7). The naphthalene peak appears weaker because of its tendency to fragment, even at only $20 \mathrm{eV}$. Fig. 8A shows that the HRMS data of the aromatic fraction of IBC101 coal extract is extremely complex (compare the low resolution spectrum previously reported [8]), but the close-up view (Fig. 8B) shows that dibenzothiophene and $\mathrm{C}_{4}$-alkylnaphthalenes can still be resolved. A resolution of 5300 implies that at a mass of $184 \mathrm{Da}$, we can expect to resolve mass differences $(\Delta \mathrm{m})$ of $35 \mathrm{mDa}$, which is adequate to distinguish between our two standard compounds $(\Delta \mathrm{m}=91 \mathrm{mDa})$. The observed masses are in good agreement with the calculated (Table 3 ). 


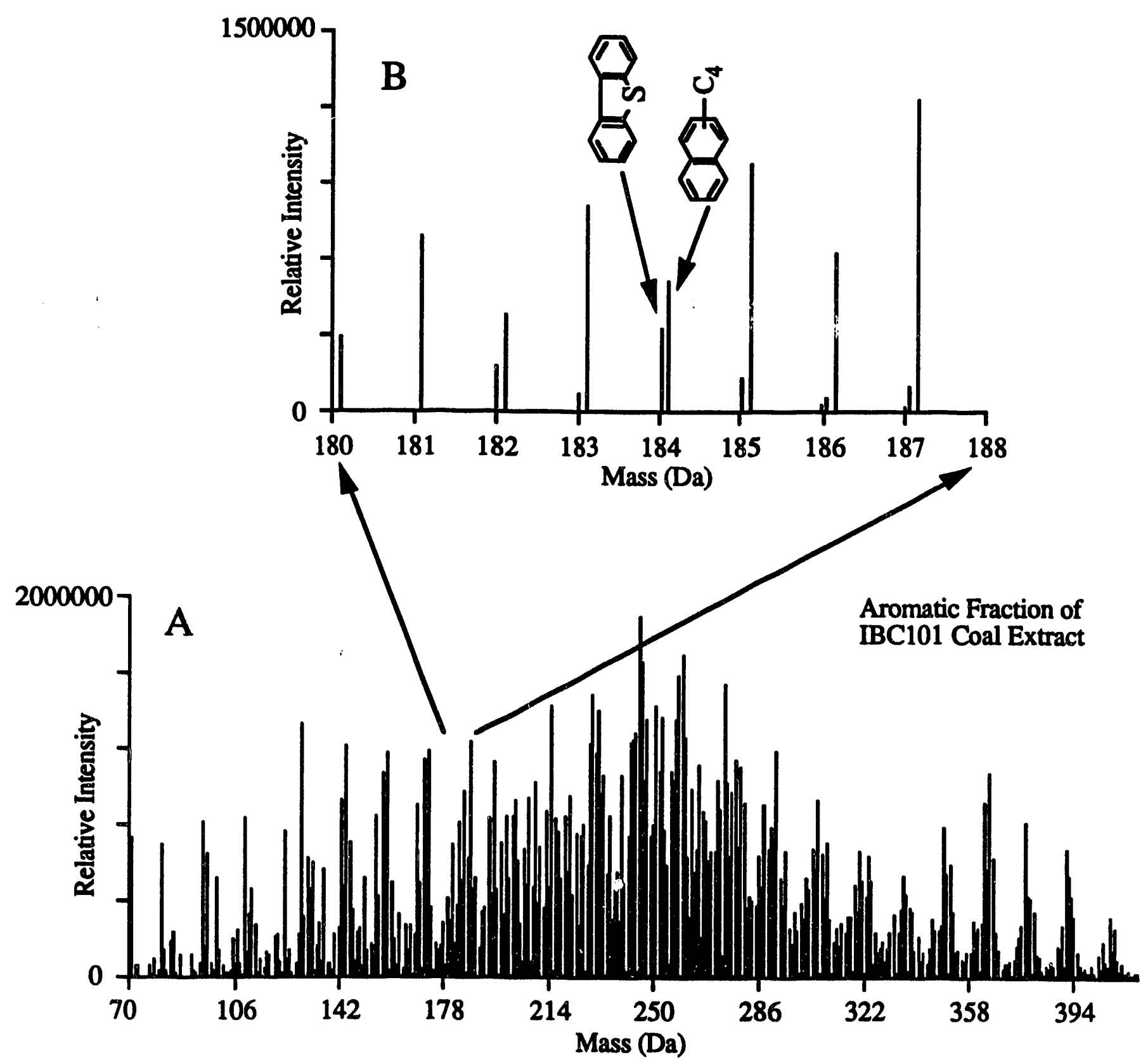

Figure 8 - HRMS spectrum of the aromatic fraction of IBC101 coal extract. A) 70 to $420 \mathrm{Da}$. B) Enlarged, 180 to $188 \mathrm{Da}$.

A more difficult test of the method is the analysis of an actual oxidation product, in this case, the first dichromate step of the extremely sulfur-rich Spanish lignite sample. The HRMS spectrum is dominated by the 163.0413 and $221.0374 \mathrm{Da}$ peaks, corresponding to the methyl esters of benzene dicarboxylic and tricarboxylic acids (Fig. 9), which are major components of this sample [9]. Note that even at the relatively "soft" $20 \mathrm{ev}$ ionization, the methyl esters preferentially form $M+(-31)$ fragments, indicating the ready loss of $-\mathrm{OCH}_{3}$ groups. We can then search the MS data for the 
$M+(-31)$ ions of the $C_{2}-$ and $C_{3}$-ATCA methyl esters, the masses of which are given in Table 3. Reasonable matches are found, shown as peaks " $a$ " and " $b$ " in the enlarged partial mass spectra in Fig. 9.

Table 3 - Calculated and observed masses. Only the most abundant isotopes $(1 \mathrm{H}, 12 \mathrm{C}, 16 \mathrm{O}, 32 \mathrm{~S})$ are used in calculations. "ME" indicates methyl ester.

$\begin{array}{lcccc}\text { Compound } & \begin{array}{c}\text { Ion } \\ \text { Type }\end{array} & \begin{array}{c}\text { Calc. } \\ \text { Mass (Da) }\end{array} & \begin{array}{c}\text { Obs. } \\ \text { Mass (Da) }\end{array} & \begin{array}{c}\text { Calc. } \\ \text { (mDa) }\end{array} \\ \begin{array}{lcccc}\text { C4-alkylnaphthalene } \\ \text { dibenzothiophene }\end{array} & M+ & 184.1270 & 184.1262 & 0.8 \\ \begin{array}{l}\text { benzene dicarbo- } \\ \text { xylic acid (ME) }\end{array} & M+(-31) & 163.0395 & 163.0413 & -1.8 \\ \begin{array}{l}\text { benzene tricarbo- } \\ \text { xylic acid (ME) }\end{array} & M+(-31) & 221.0450 & 221.0374 & 7.6 \\ \begin{array}{l}\text { C2-ATCA (ME) } \\ \text { C3-ATCA (ME) }\end{array} & M+(-31) & 169.0323 & 169.0315 & 0.8 \\ \text { M+(-31) } & 183.0479 & 183.0555 & -7.6\end{array}$

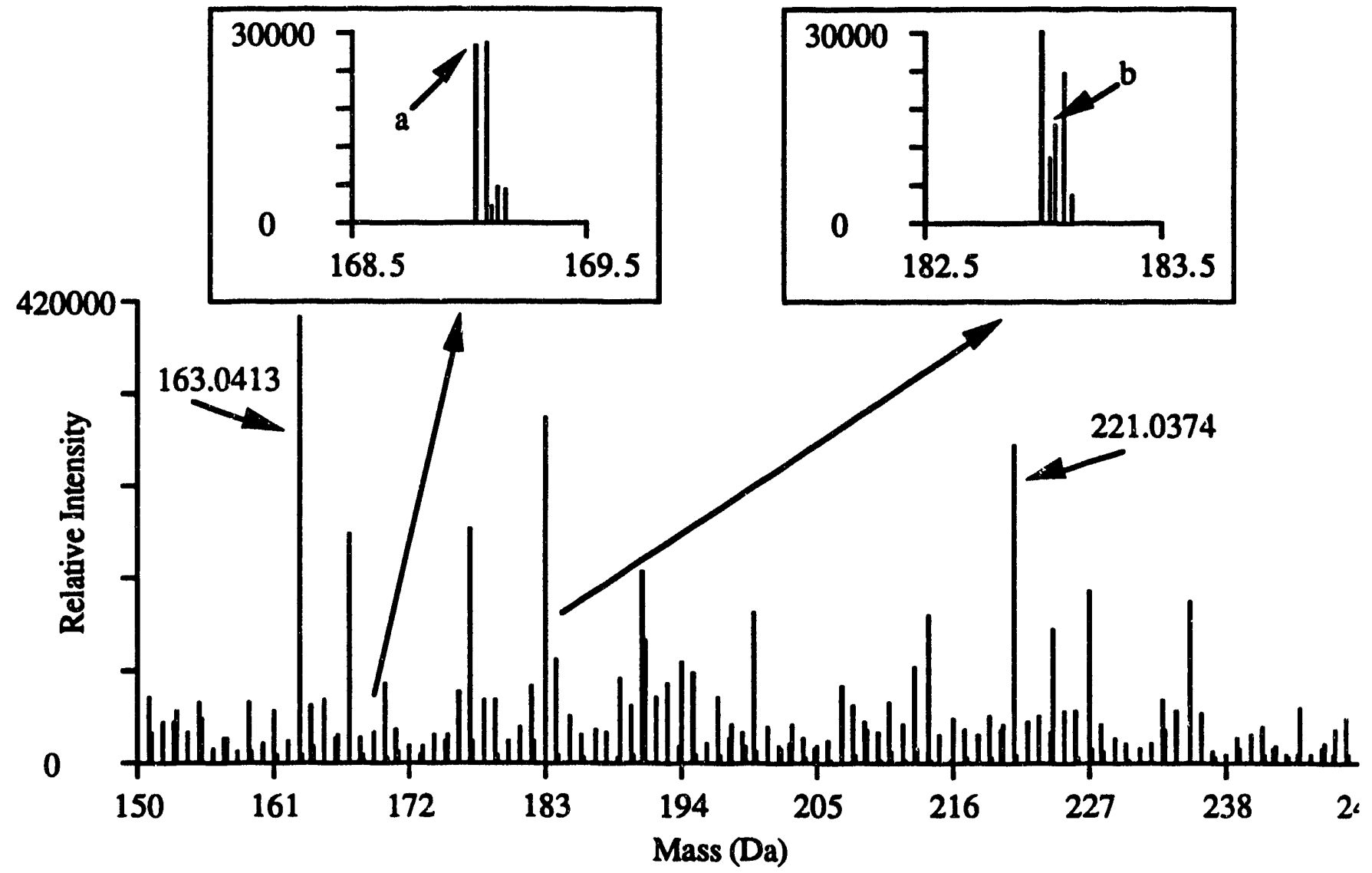

Figure 9 - HRMS spectrum of the methylated dichromate oxidation products (1st step) of the "Spanish lignite" sample. Two enlargements are shown, with mass peaks "a" and "b" discussed in the text. 


\section{CONCLUSIONS AND RECOMOKENDATIONS}

1) Standard density gradient centrifugation successfully isolated vitrinite from the IBC101 coal, whereas the multistep high resolution method was required to isolate liptinite and inertinite macerals. The technique was not able to further fractionate the liptinite group into its constituent cutinite, resinite and sporinite macerals, probably because of the low concentration of liptinites in this samples.

2) Analytical pyrolysis-gas chromitography, operating with either the sulfur selective flame photometric detector (pyGC-PFD) or a mass spectrometer (py-GC/MS), provides distinctive organosulfur "fingerprints" for all coal, asphaltene and maceral samples analyzed to date.

3) Asphaltenes from low (high volatile bituminous $C$ ) and high rank (medium volatile bituminous) coals from the Lower kittanning seam are readily differentiated by the alkylthiophene distributions on their py-GC/MS traces. Elemental sulfur dominates the py-GC/MS trace of the asphaltenes of a low volatile bituminous sample.

4) PY-GC/MS is advantageous, as it provides detailed information about the hydrocarbon components in addition to the organosulfur compounds. However, py-GC-FPD is simpler and less expensive and is the recommended method for situations in which sulfur content is the prime concern.

5) Both py-GC methods are superior to oxidative degradation techniques in that they are permit direct, one-step microscale analysis, requiring only a minimum of sample preparation.

6) Distinctive chromatographic profiles are also achieved using the methylated dichromate oxidation products of coals, asphaltenes and macerals. Alkylthiophene carboxylic acid derivatives (ATCA compounds) continue to be seen in sulfurrich samples, but are not readily detectable in the sulfur lean coals, such as IBC109. In general, when choosing an analytical procedure for application on a routine basis, the extensive wet chemical preparation required for the oxidation methods is a serious disadvantage. There are also problems in reproducibility, apparently due to the sensitivity of product distribution to amount of starting material.

7) Reasonable matches for ATCA compound mass spectral ions have been found in the direct probe, low voltage, high resolution MS data set, collected on the methylated dichromate oxidation products of the sulfur-rich spanish lignite sample, providing an additional line of evidence confirming the presence of such compounds.

\section{REFERENCES}

1) Kruge M.A. and Palmer S.R. (1992). ICCI Quarterly Technical Report, 1 Sep. 1992 - 30 Nov. 1992.

2) Kruge M.A., Palmer S.R. and Baudet N. (1991). CRSC Quarterly Technical Report, 1 Sep. 1991 - 30 Nov. 1991. 
3) Crelling, J.C. (1989). Am. Chem. Soc. Div. Fuel Chem. Prepr. 34 (1), 249-255.

4) Kruge M.A. and Palmer S.R. (1993). ICCI Quarterly Technical Report, 1 Dec. 1992 - 28 Feb. 1993.

5) Sinninghe Damsté J.S., de las Heras F.X.C. and de Leeuw J.W. (1992). J. Chrom. 607:361-376.

6) Sinninghe Damsté J.S. and de Leeuw J.W. (1992). Fuel Process. Tech. 30:109-178.

7) Sinninghe Damsté J.S., Eglinton T.I. and de Leeuw J.W. (1992). Geochim. Cosmochim. Acta 56:1743-1751.

8) Kruge M.A.. Palmer S.R. and Baudet N. (1992). CRSC Quarterly Technical Report, 1 Dec. 1991 - 28 Feb. 1992.

9) Kruge M.A., Palmer S.R. and Baudet N. (1992). CRSC Final Technical Report, 1 Sep. 1991 - 31 Oct. 1992. 
PROJECT MANAGEMENT REPORT

1 March through 31 May, 1993.

Project Title: ANALYSIS OF ORGANIC SULFOR AND NITROGEN IN

COAI VIA TANDEM DEGRADATION METHODS

Principal Investigator: Michael A. Kruge, Assoc. Professor, Dept. of Geology, Southern Illinois

Co-Investigator: University, Carbondale, IL 62901

Stephen R. Palmer, Assoc. Scientist, Dept. of Geology, Southern IIlinois

University, Carboncicile, IL 62901

Project Manager:

Ken Ho, CRSC

The project is proceeding essentially on schedule and budget. More time will be needed to complete the gel permeation chromatography and GC-TSD. 


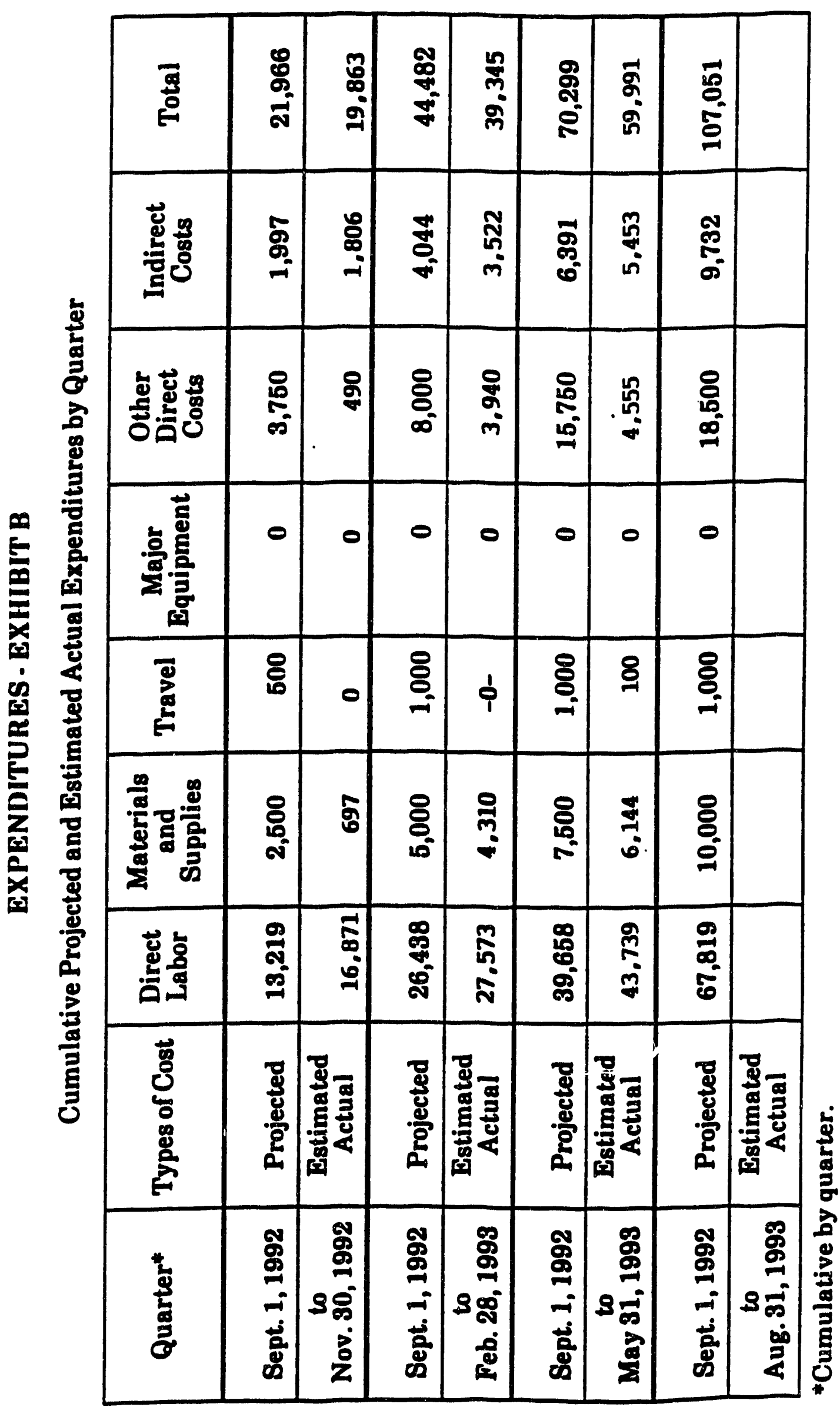




\section{CUMULATIVE COSTS BY QUARTER - EXHIBIT C}

\section{Analysis of Organic Sulfur and Nitrogen in Coal via Tandem Degradation Methods}

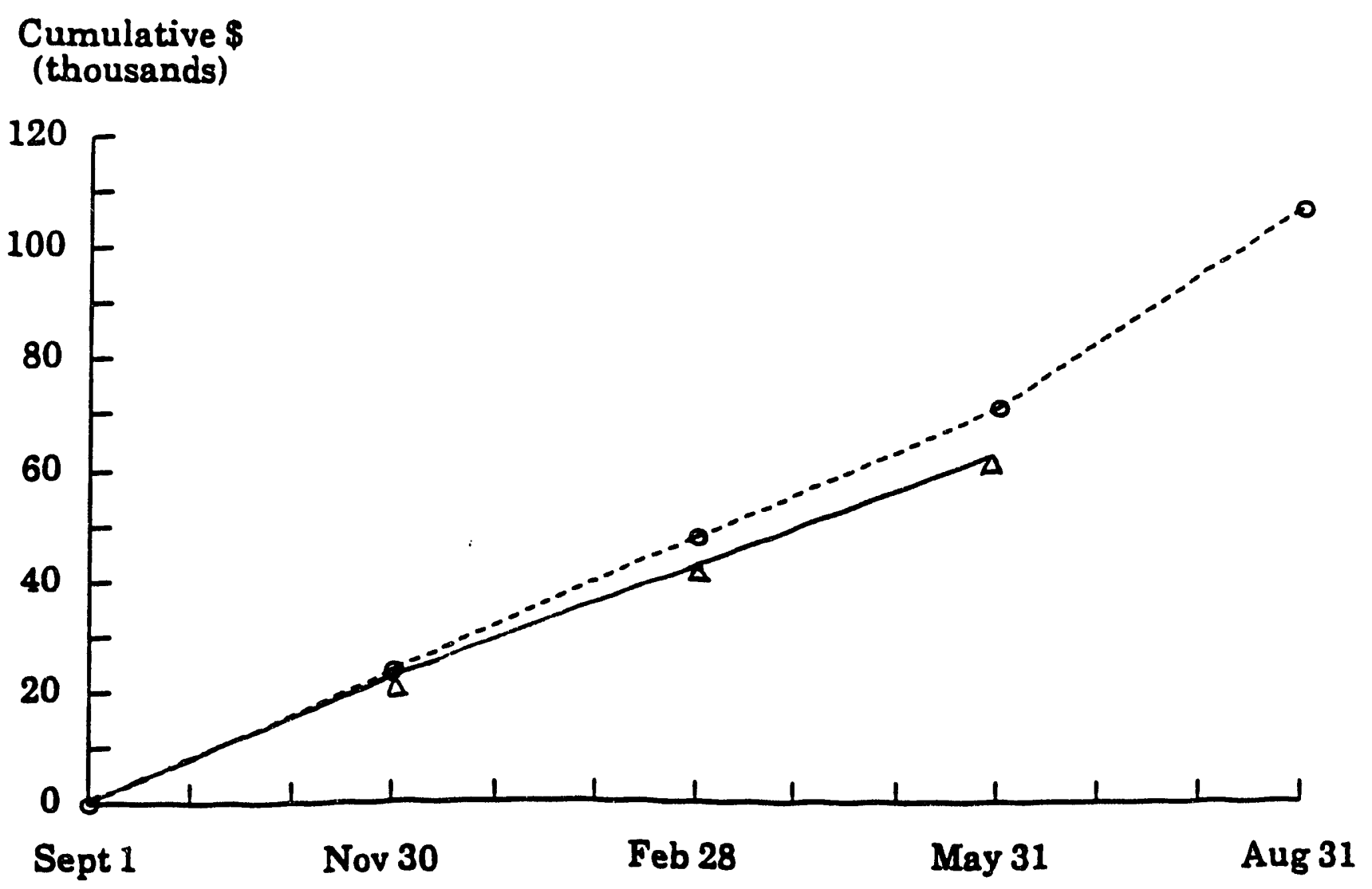

Months and Quarters

$0=$ Projected Expenditures

$\Delta=$ Actual Expenditures

Total CRSC Award $\$ 107,051$ 


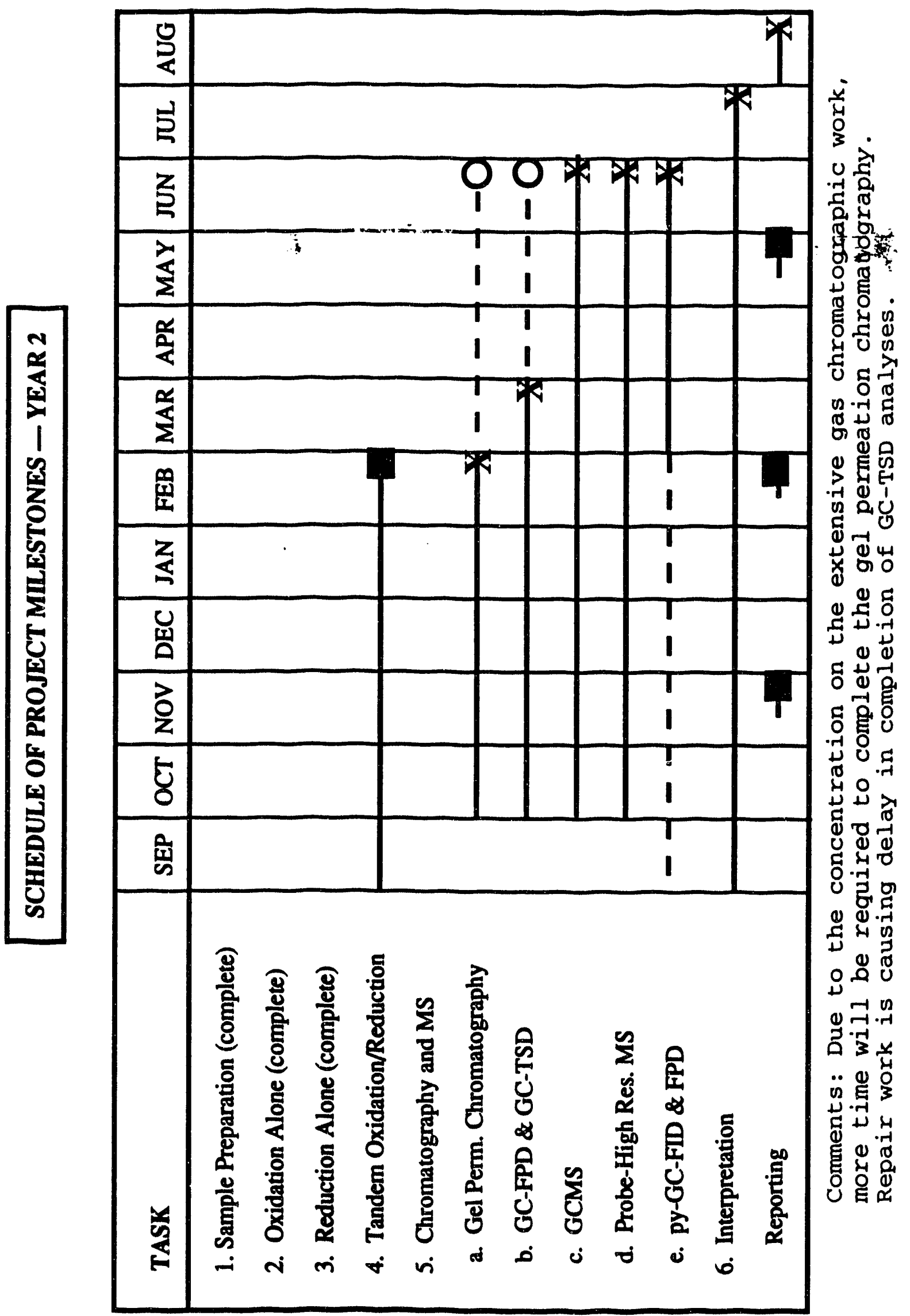



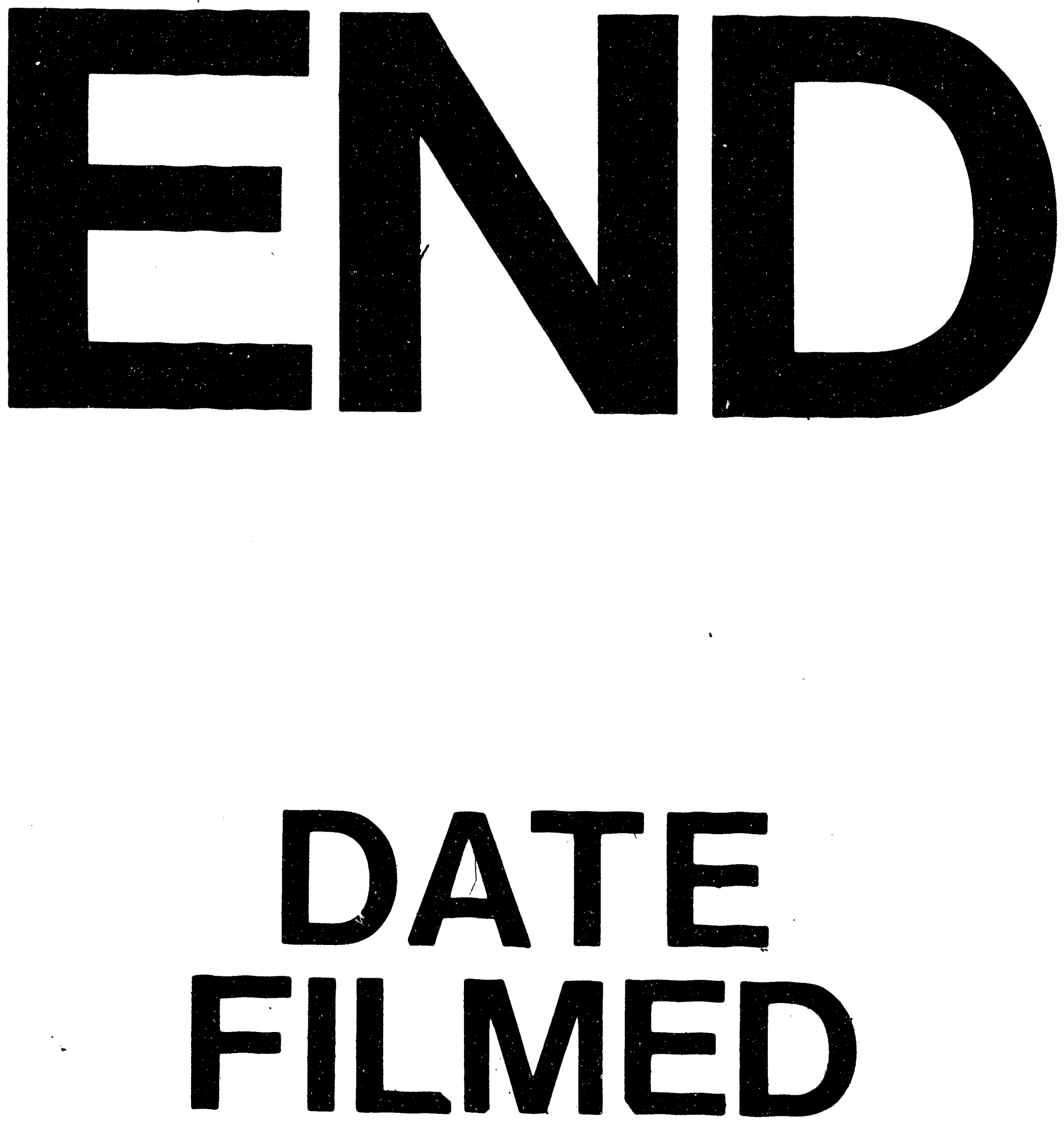

1

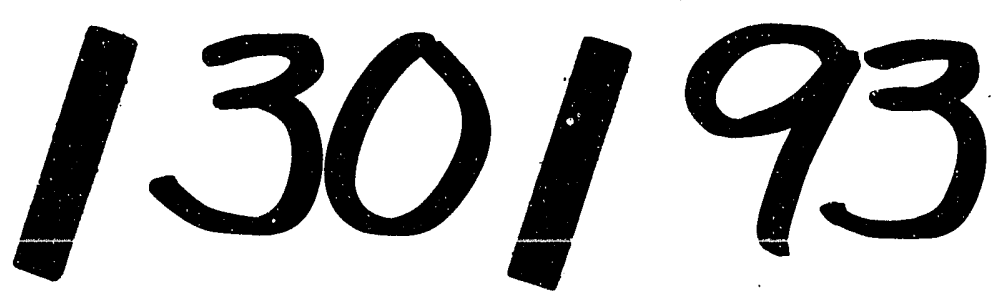


